\title{
The Motivational Factor of Erasmus Students at the University
}

\author{
Javier Fombona ${ }^{1}$, Celestino Rodríguez ${ }^{2} \& \mathrm{M}^{\mathrm{a}}$. Ángeles Pascual Sevillano ${ }^{1}$ \\ ${ }^{1}$ Faculty of Teacher Training and Education, University of Oviedo, Spain \\ ${ }^{2}$ Faculty of Psychology, University of Oviedo, Spain \\ Correspondence: Celestino Rodríguez, Department of Psychology, University of Oviedo, Plaza Feijoo s/n, \\ Oviedo 33003, Spain. Tel: 34-985-103-411. Fax: 34-985-104-147. E-mail: rodriguezcelestino@uniovi.es
}

Received: February 3, 2013 Accepted: February 17, 2013 Online Published: March 4, 2013

doi:10.5539/ies.v6n4p1 URL: http://dx.doi.org/10.5539/ies.v6n4p1

\begin{abstract}
This study involved 377 ERASMUS students from the University of Oviedo in an academic year. An ad-hoc questionnaire was applied in on-line format to determine students' perceptions and opinions and to understand the motivations that impel them to participate in these activities and their degree of satisfaction. The study analyzes the process of Erasmus mobility, noting that, as a result of the stay, the students describe their mastery of the host country language as good or excellent in most cases. Academic and cultural factors, the desire to get to know a new environment and to have a European experience impel most of the students to travel abroad. Job prospects are another motivating factor, and the overall assessment of the planned stay is acceptable, good or excellent in most cases.
\end{abstract}

Keywords: motivation, ERASMUS, lifelong learning program, university

\section{Introduction}

\subsection{State of Art}

One of the characteristics of the new international university relations scenario is its increasing level of economic and cultural exchanges. This dynamic supports the proposal of a common Europe facing the challenge of its diversity. Ideas about internationalization and globalization do not always refer to the same goals; for instance, cooperation is based on mutual trust, whereas business strategies and interests focus on principles of competence and conquering markets (Teichler, 2009).

The Ministerial Conference of the Process of Leuven/Louvain-la-Neuve of 2009 set the goal of $20 \%$ of European graduate students with studies or practicum abroad for the year 2020. This turns academic mobility into one of the most important aspects of the common European space. Students' international mobility in Europe favors a sense of fraternity, but it is also an investment in future development, resulting in the relocation of people with high research capacities (Rindoks, 2010). Various studies have revealed the relation between these stays in another country and the phenomenon of migration of academicians, stressing that its long-term results should be analyzed (Hoffman, 2009). In Europe, specific actions such as equating the studies carried out and their quantification in ECTS credits have facilitated academic acknowledgement of the training undertaken, also implying the validity of such training across Europe. This new framework of work exchanges is considered an opportunity and a priority for development in some countries, such as Latvia (Bluma, 2009; European Commission, 2010).

The European Parliament Decision (nr 1720/2006/CE) established the action Program in the field of Lifelong Learning (Lifelong Learning Programme - hereafter, LLP), which signalled the final stage of the Bologna process initiated in 1999, defining the European space of higher teaching for 2010. Its specific goals were: a) to develop quality and innovative PLL; b) to support the common Europe; c) to promote lifelong learning opportunities for social cohesion, active citizenship, intercultural dialogue, equality of men and women; e) to help creativity, competitiveness, employment and entrepreneurial growth; f) to extend lifelong learning to all ages, to students with special needs and to disadvantaged students; g) to promote learning languages; $h$ ) to support the development of contents based on Information and Communication Technologies (ICTs); and i) to respect human rights and democracy. 
The new European framework in the year 2020 is grounded on the institutions of higher education; they will be the impellers of the society of knowledge and will contribute to training the active population. For this purpose, higher teaching has been made uniform (Commission of the European Communities, 2006) and (Commission of the European Communities, 2009a and 2009b), with the following changes:

- Curricular: a system of three cycles (degree, master, doctorate), learning based on competence, flexible learning itineraries, acknowledgement of qualifications and competences, and mobility.

- Management reformation: autonomy and responsibility of the institutions.

- Funding reformation: diversification of income, enrolment fees, equitable assistance, and specific funding of the EU.

The goals of the LLP now focus on a new strategy for European development for 2020: sustainable growth, advanced knowledge, united citizenship in its society, and access to lifelong learning as a formula against unemployment. The strategic goals promote academic mobility and the increase of the quality and efficacy of education to improve levels of occupational insertion. In this sense, we underline the acknowledgement of the qualifications and flexible learning itineraries, as well as the acquisition of key transversal competences and the association with business and labour spheres (European Union Council, 2009).

Erasmus is the subprogram of Higher Teaching and Higher Professional Training. Its international cooperative actions have made it the most important program in the history of humanity, according to the Commissioner of Education and Culture of the European Union (Reding, 2004). In the EAC/49/10 of 2011 summons, a total of 1,065 million euros was granted, an increase of $4.6 \%$ over the previous year. Subsequently, specification of aids granted to each country has varied according to factors such as the type of project or the number of participant countries. Student mobility involved 213,266 people distributed among the twenty-seven states of the European Union, Iceland, Liechtenstein, Norway, Switzerland, Croatia, and Turkey.

The specific Erasmus goals (European Parliament, 2006) promote the attainment of a European Space for Higher Education by reinforcement of training and innovation. The operational goals are as follows:

a) To improve students' and teachers' mobility in Europe qualitatively and quantitatively, achieving stays for three million people;

b) To improve the quality and volume of multilateral cooperation among European institutions of higher education;

c) To increase the transparency and compatibility of qualifications of higher education and higher professional training;

d) To improve cooperation among educational institutions and businesses;

e) To facilitate the development of tertiary level innovative educational practices, as well as their transfer, even between countries;

f) To support the development of contents, services, pedagogies, and innovative lifelong learning practices based on ICTs.

Decision $\mathrm{n}^{\circ} 1720 / 2006 / \mathrm{CE}$ has also set other priorities for Erasmus actions: the organization of Intensive Erasmus Language Courses in minority languages for mobile students, and short Intensive Programs focusing on specific study activities among various universities. In this sense, this activity should be multidisciplinary and oriented towards business studies, social sciences, arts, humanities, languages, law, and the development of business competences.

In this context, the Erasmus subprogram specifies these challenges through the following actions:

- Academic mobility

- Accomplishment of students' practicum and cooperation with businesses

- Courses of minority languages

- Compatibility of qualifications

- Inter-institutional cooperation

- Inclusion of ICTs

- Intensive training programs 


\subsection{Aim and Hypotheses}

In view of the promotion of such mobility, it is suggested that we should observe students' responses and determine whether they accept the proposals of the Erasmus program (Makal, 2007). Thus, according to these guidelines, the goal of this study is to determine whether these directives are present in the perceptions and motivations that impel students from a Spanish university to participate in these LLP actions during their Erasmus stay.

\section{Method}

\subsection{Participant Characteristics}

The University of Oviedo is a higher public institution with 24.890 students enrolled. A total of 377 students went abroad with the Erasmus program during the academic year 2009/2010, of whom 157 were male and 220 were female (Table 1). Most of the students were from the region of Asturias, although a small percentage of students came from the bordering regions (Castilla-León, Galicia, and Cantabria).

Table 1. Demographic characteristics of the sample and requested destination

\begin{tabular}{|c|c|c|c|c|c|c|c|}
\hline $\begin{array}{l}\text { Age in } \\
\text { years }\end{array}$ & $\begin{array}{l}\% \text { of } \\
\text { the } \\
\text { sample }\end{array}$ & $\begin{array}{l}\text { Educational area of } \\
\text { provenance }\end{array}$ & $\begin{array}{l}\% \text { of the } \\
\text { sample }\end{array}$ & $\begin{array}{l}\text { Destination } \\
\text { (country) }\end{array}$ & $\begin{array}{l}\% \text { of the } \\
\text { sample }\end{array}$ & $\begin{array}{l}\text { Teaching } \\
\text { language }\end{array}$ & $\begin{array}{l}\% \text { of } \\
\text { the } \\
\text { sample }\end{array}$ \\
\hline 22 & 10.8 & $\begin{array}{l}\text { Business } \\
\text { administration }\end{array}$ & 18.5 & Italy & 21.2 & English & 64.5 \\
\hline 23 & 20.7 & $\begin{array}{l}\text { Biology and } \\
\text { biochemistry }\end{array}$ & 6.53 & England & 19.0 & Italian & 15.1 \\
\hline 24 & 20.7 & Education & 6.25 & Germany & 11.2 & German & 12.7 \\
\hline 25 & 16 & Law & 5.4 & France & 8.2 & French & 12.2 \\
\hline 26 & 13.3 & $\begin{array}{l}\text { Electronics and } \\
\text { automation }\end{array}$ & 4.54 & Bulgaria & 6.0 & Portuguese & 1.86 \\
\hline 27 & 7.4 & Economics & 3.4 & Poland & 4.7 & Danish & 1.33 \\
\hline 28 & 6.3 & $\begin{array}{l}\text { History and } \\
\text { archaeology }\end{array}$ & 1.7 & Norway & 4.2 & Finnish & 1.06 \\
\hline 29 & 2.2 & $\begin{array}{l}\text { Electricity and } \\
\text { energy }\end{array}$ & 0.56 & Sweden & 3.6 & Turkish & 1.06 \\
\hline 30 & 1.1 & $\begin{array}{l}\text { Nursing, obstetrics } \\
\text { and physiotherapy }\end{array}$ & 0.56 & Holland & 3.0 & Czech & 0.8 \\
\hline 31 & 0.5 & Arts & 0.29 & Austria & 2.7 & Spanish & 0.8 \\
\hline 35 & 0.2 & Odontology studies & 0.29 & $\begin{array}{l}\text { Czech } \\
\text { Republic }\end{array}$ & 2.6 & Greek & 0.8 \\
\hline 38 & 0.56 & $\begin{array}{l}\text { Languages and } \\
\text { Philology }\end{array}$ & 9.94 & Denmark & 2.5 & Polish & 0.53 \\
\hline \multirow[t]{10}{*}{46} & 0.20 & Earth Sciences & 4.82 & Portugal & 2.4 & Russian & 0.27 \\
\hline & & Statistics & 0.85 & Belgium & 2.0 & Norwegian & 0.27 \\
\hline & & & & Greece & 1.5 & & \\
\hline & & & & Ireland & 1.2 & & \\
\hline & & & & Norway & 1.2 & & \\
\hline & & & & Hungary & 0.9 & & \\
\hline & & & & Turkey & 0.9 & & \\
\hline & & & & Slovakia & 0.8 & & \\
\hline & & & & Lithuania & 0.3 & & \\
\hline & & & & Slovenia & 0.3 & & \\
\hline
\end{tabular}

\subsection{Assessment Instrument}

The questionnaire we used was available through the institutional website of the University of Oviedo and it was completed after the students had returned. In the questionnaire, students were requested to reveal their 
impressions and motivations about their Erasmus stay both through closed-ended and open-response questions. The questions were divided into 10 sections. For more information and questionnaire format is available in the website: http://www.uniovi.net/zope/organosgobierno/unipersonales/vicerrectorados/vicd/encuestas/Erasmus

The initial data referred to the identification of the surveyed student (name and surnames, ID, sex, city of origin, area of studies, and e-mail address). In this way, the data is linked to the specific person who did the student exchange, increasing response reliability.

The rest of the questionnaire includes 35 items, grouped into the following categories:

- Support and information

- Accommodation and infrastructures

- Academic aspects

- Language

- Economic aspects

- Personal experience.

\subsection{Design and Data Analysis}

An ex post facto design was used to determine the perceptions and motivations that impel students from a Spanish university to participate in these LLP actions during their Erasmus stay. The data obtained were analysed by means of individual descriptive and quantitative analysis

\subsection{Variables}

To determine the European directives of the LLP, this study was based on the European normative published to this effect, as well as on the annual reports and statistics published by the European Commission and other literature on international mobility from the European Union. Derived from content analysis of these legislative texts, we observe that this European program pursues the following main goals, LLP directives: Academic and professional results of the mobility, Quality and universalization of Learning, Conception of community and European cohesion, language issues, and Flexibility and academic equivalences.

For this purpose, these six aspects were selected as variables to be quantified in the perceptions and motivations of the students to go abroad on an Erasmus student exchange, in addition to the global impact of the experience.

\section{Results}

\subsection{Global Impact of the Experience}

The global actions of the Erasmus program were positively rated in $90.4 \%$ of the cases. Moreover, the duration of the stay was considered adequate or even short in $98 \%$ of the cases, and it was considered academically acceptable, good, or excellent (86.2\%), with positive personal rating reaching 91.4\% (Table 2).

Table 2. Global results and impact of the ERASMUS stay

\begin{tabular}{llllll}
\hline Personal appraisal of the stay & Responses & $\%$ & Academic rating of the stay & Responses & $\%$ \\
\hline Negative & 1 & 0.27 & Negative & 6 & 1.59 \\
Poor & 1 & 0.27 & Poor & 16 & 4.24 \\
Acceptable & 88 & 23.3 & Acceptable & 88 & 23.3 \\
Good & 100 & 26.5 & Good & 125 & 33.2 \\
Excellent & 157 & 41.6 & Excellent & 29.7 \\
Global assessment of the stay & Responses & $\%$ & Personal rating of the duration of the & Responses & $\%$ \\
& & & stay abroad & 305 & 81 \\
Negative & 2 & 0.53 & Adequate & 64 & 17 \\
Poor & 4 & 1.06 & Short & 7 & 2 \\
Acceptable & 13 & 3.45 & Long & & \\
Good & 206 & 54.6 & & & \\
Excellent & 122 & 32.4 & &
\end{tabular}




\subsection{Analysis of the Impact of the LLP Directives in the ERASMUS Students of the University of Oviedo Academic and Professional Results of the Exchange}

The students' own motivation, which impels them to obtain academic and professional benefits, can be considered an intrinsic stimulus (Table 3). The open questions revealed the motivational factor of mastering a new language in $56 \%$ of the responses. To a lesser extent, students refer to knowledge of a new educational methodology (14.9\%), achieving an independent life (10.2\%), personal development $(6.8 \%)$, and increased job options (4\%).

Table 3. Motivational factors of the participants in the ERASMUS program

\begin{tabular}{lll}
\hline $\begin{array}{l}\text { Factors that motivated the student } \\
\text { to go abroad }\end{array}$ & Responses & $\%$ \\
\hline European experience & 203 & 53.8 \\
Academic & 195 & 51.7 \\
Cultural & 190 & 50.4 \\
A new foreign environment & 167 & 44.3 \\
Career planning & 102 & 27.1 \\
Friendships & 38 & 10.1 \\
\hline
\end{tabular}

\subsection{Quality and Universalization of Learning}

To appraise the impact of this pattern on the students, we quantified two factors: the extrinsic positive reinforcement of the Informative Support and the influence of the Economic Support.

Informative Support. This is a sensitizing action for all students, which is carried out through informative meetings, and broadcast through the institutional website and systematic emailing of information. It presents the appeal of student exchange related to the advantages of the LLP. Moreover, personal issues such as generating an international dimension of one's $\mathrm{CV}$, helping to find work, consolidating a second language, and getting to know another institution and culture, are also presented. This information is considered acceptable, good or excellent in $78.7 \%$ of the cases (Table 4 ).

Table 4. Results detected for the extrinsic factor informative support

\begin{tabular}{|c|c|c|c|c|c|}
\hline $\begin{array}{l}\text { Your source of general } \\
\text { information and of the study } \\
\text { program at your destination } \\
\text { was... }\end{array}$ & Responses & $\%$ & $\begin{array}{l}\text { When you arrived at your } \\
\text { destination institution, you } \\
\text { were offered... }\end{array}$ & Responses & $\%$ \\
\hline Institution of origin & 210 & 55.7 & Welcome act & 158 & 41.9 \\
\hline Destination Institution & 141 & 37.4 & Informative session & 155 & 41.1 \\
\hline Internet & 188 & 49.9 & Orientation program & 94 & 24.9 \\
\hline Other & 34 & 9.02 & $\begin{array}{l}\text { During your stay, reception } \\
\text { acts were organized... }\end{array}$ & Responses & $\%$ \\
\hline $\begin{array}{l}\text { The utility of this information } \\
\text { was... }\end{array}$ & Responses & $\%$ & Yes & 310 & 82 \\
\hline Negative & 4 & 1.06 & No & 68 & 18 \\
\hline Poor & 46 & 12.2 & $\begin{array}{l}\text { You received adequate } \\
\text { support from the institution of } \\
\text { origin or the destination } \\
\text { institution... }\end{array}$ & Responses & $\%$ \\
\hline Acceptable & 138 & 36.6 & Negative & 4 & 1.06 \\
\hline Good & 140 & 37.1 & Poor & 40 & 10.6 \\
\hline Excellent & 19 & 5.04 & Acceptable & 109 & 28.9 \\
\hline \multirow[t]{2}{*}{ Did not reply } & 21 & 5.57 & Good & 169 & 44.8 \\
\hline & & & Excellent & 25 & 6.63 \\
\hline
\end{tabular}


Economic support Financial aid can be considered, a priori, an indeterminate factor of influence because it can be a stimulus in the case of a comfortable economic situation or a difficulty in more disadvantaged situations, as economic support is variable and is only received after completing the stay.

In these student exchanges, Thorn (2009) differentiated motivation resulting from external and extrinsic reinforcement from intrinsic motivation, considered as the manifestation of the outcome of a personal choice. He also mentions other sources of accidental influence on certain interests that can have positive or negative impact.

The results show that this support partially or totally covers expenses in $63.6 \%$ of the cases. Therefore, this aid is complemented by economic support from the family ( $57 \%$ of the cases). The mean expense is between 500 and $700 €$ for $67.9 \%$ of the students, and it mainly involves non-academic goods and services, except for $21 \%$ of the cases, who also had to pay for some other type of fees at the host institution. Another motivator is that student of this program do not have to pay registration or enrolment fees at the destination.

\subsection{Conception of Community and European Cohesion}

The impact of this pattern was appraised by analysis of the level of integration with the host society. Erasmus students find a high level of acceptance in foreign settings. For instance, the students were accommodated in specific university establishments, and in a similar proportion, in homes or with families from the community (Table 5). It is noteworthy that, initially, only $10.1 \%$ considered friendship as a motivational goal, but subsequently, $73.8 \%$ of the surveyed stated they found the relationship with their local classmates to be acceptable, good, or excellent.

Table 5. Results of the intrinsic stimulus factor immersion in the community

\begin{tabular}{lll}
\hline Type of accommodation during the stay & Responses & $\%$ \\
\hline University & 163 & 43,2 \\
Apartment & 110 & 29,2 \\
Private home & 19 & 5,04 \\
Families and other & 25 & 6,63 \\
...provided accommodation & Responses & $\%$ \\
University office & 156 & 41,4 \\
Friends/family & 28 & 7,43 \\
Private offer & 85 & 22,5 \\
Other ads and Internet & 78 & 20,7 \\
Degree of integration with the local student community & Responses & $\%$ \\
Negative & 8 & 2.12 \\
Poor & 54 & 14.3 \\
Acceptable & 107 & 28.4 \\
Good & 128 & 34 \\
Excellent & 43 & 11.4 \\
\hline
\end{tabular}

In this sense, in an open question about the most positive aspects of the stay, $34 \%$ referred to forging personal links of friendship, and $42.8 \%$ mentioned the cultural enrichment of living in another human environment.

\subsection{Language Issue}

The language factor can either be a motivator in cases in which the person feels stimulated and able to deal with relationships in another language, or it can be a barrier due to lack of knowledge and fear of not being able to communicate in the destination language. Thus, in the study of Fernández Olmos (2010, p. 118), it is considered a demotivator in $77.8 \%$ of the cases, and a stimulator in $68.8 \%$. The process of Erasmus applicant selection hinders the mobility of people with a low language level. The test questions are progressively more difficult, in order to determine the student's level. 
The results show that $61 \%$ of the students received linguistic training before and/or during their stay abroad. The institution of origin was responsible for these courses in $5 \%$ of the cases, the destination institution in $38 \%$, and in $52 \%$ of the cases, it was not clear who was responsible for this training.

The open questions show that the language factor is noteworthy in $56 \%$ of the cases as one of the most important motivational elements. There is a significant increase in the mastery of the new language after the student exchange. Of the surveyed, $22 \%$ stated that their mastery of the language before the stay was poor, but this percentage sank to $1 \%$ after the stay. Likewise, before the stay, $25 \%$ considered their language level to be good, and this increased to $50 \%$ after the stay. The exchange had a positive impact on language, as $7 \%$ stated that their mastery was excellent before the stay, and this percentage reached $36 \%$ after the stay.

\subsection{Flexibility and Academic Equivalences}

The degree of flexibility and acknowledgement of the proposed academic studies abroad are considered an influential factor of extrinsic positive reinforcement.

The students decide which subjects they want to study at the destination institution, and they are equated with other subjects from the university of origin, equating the total number of credits and the typology. Changes in the choice of materials at the destination are also accepted after the exchange has begun.

In the study carried out, we verified that, in $91 \%$ of the cases, the studies are agreed on before the stay. After returning, the academic equivalence of this period of studies was obtained in $89 \%$ of the cases, and in $38 \%$, supplementary credits were obtained upon completing language courses.

\section{Discussion}

Informative support is a positive stimulus in $78.7 \%$ of the cases, and this element is repeated in other countries, as noted by Kirsch and Beernaert (2011) in his analysis of student exchanges in the French community of Belgium, where it also reaches $88 \%$.

In our analysis, it is concluded that the economic support is sufficient (63.6\%), which is coherent with that of the study of Kirsch and Beernaert (2011, p. 73). Also, the degree of student integration with the classmates reaches an acceptable, good, or excellent level in $73.8 \%$ of the cases, the same amount as that obtained by Kirsch and Beernaert (2011, p. 60) in Belgium. Likewise, the high levels of study equivalence and academic flexibility also coincide.

Some of our results are similar to the work of Fernández Olmos $(2010$, p. 117), in which the positive motivational factors of these actions are rated: international experience (73.3\%) and personal development (66.6\%), although, in addition to the factors of Fernández Olmos, job opportunities are considered to a greater extent $(66.6 \%)$. This author also underlines the following demotivators for mobility: lack of knowledge of the language (77.8\%), funding difficulties (75.6\%), and difficulties to find adequate accommodation $(57.8 \%)$.

The climate of personal satisfaction with these programs is high, reaching $91.4 \%$ of positive ratings, and, at the academic level, $86.2 \%$ of the opinions were satisfactory. These data rise to 97 and $96 \%$, respectively, in the study of Kirsch and Beernaert (2011, p. 101).

Students who participate in these programs have a profile with high academic performance, and this suggests more independence and autonomy over their training context (Arias, et al., 2010, p. 810). This circumstance promotes stimulus and motivation to achieve good academic and professional outcomes from the exchange, and this is confirmed by the results of the initial motivation in the analyzed directive of academic and global outcomes of the stay.

Thorn (2009) described a series of motivators in international student exchange options, such as cultural opportunity, academic development, and economic and professional motivations, interest in human relations, the appeal of the mere fact of travelling and lust for adventure. These factors vary as a function of gender, location, and socioeconomic level. Our data are in accordance with Kirsch and Beernaert (2011) for the case of Belgium, in which the following motivators are noteworthy: practicing a language, foreign adventure, cultural factors, being independent, academic factors, European experience, and professional development. But we coincide with Findlay et al. (2012) in stating that, currently, the theories that explain mobility should address more profound concepts related to individual life plans and the reputation associated with certain destinations. This traces a differential geography of students' interests.

Erasmus involves more than two million people, suggesting the existence of a micro-culture that is positively considered and tends to increase. The noteworthy factors that motivate people to participate in these actions are: 
learning a language, getting to know a new culture, new people, other ways of teaching, the experience of travelling, forging new friendships, and developing the academic field.

The prior informative activity about the exchanges generates positive expectations. The economic issue is also a decisive element in the initial decisions.

The growing need to develop valid competences for students' professional future is an element that stimulates the creation of a syllabus with European dimensions, especially in the consolidation of a language, mainly English, as well as the creation of opportunities in other academic and professional settings.

Two variables that impel the Erasmus program so it is positively considered are the degree of integration with the local students and the level of acceptance in the host society. This is particularly important in the resulting trinomial: exchange, friendship, and favourable context for development. These circumstances can be a response to the efforts of the administrations to promote the Erasmus actions and to the high levels of economic investment it receives. And it can be the way towards a Europe of solidary citizens, whose development is based on links of cooperation and the creation of a common awareness.

\section{References}

Arias, J. D., Martínez Vicente, J., Peralta Sánchez, F., \& García Berbén, A. (2010). Perception of the teaching-learning process and academic achievement in diverse instructional contexts of Higher Education. Psicothema, 22(4), 806-812.

Bluma, E. (2009). Mobility study of ERASMUS integration in education system in Latvia. Rezekne: Rezekne Higher Educ Inst-Rezeknes Augstskola.

Commission of the European Communities. (2006). Delivering on the modernisation agenda for universities: Education, research and innovation. Communication from the Commission to the Council and the European Parliament, Brussels, $\operatorname{COM}(2006) 208$ final. Retrieved October 2, 2011, from http://eur-lex.europa.eu/LexUriServ/LexUriServ.do?uri=COM:2006:0208:FIN:ES:PDF

Commission of the European Communities. (2009a). A new partnership for the modernisation of universities: The EU Forum for University Business Dialogue. Communication from the Commission to the Council and the European Parliament, Brussels, $\operatorname{COM}(2009) 158$ final. Retrieved November 6, 2011, from http://ec.europa.eu/education/higher-education/doc/business/com158_en.pdf

Commission of the European Communities. (2009b). Report on progress in quality assurance in higher education. Report from the Commission to the Council, to the European Parliament, to the European Economic and Social Committee and to the Committee of the Regions COM (2009) 487 final. Retrieved from http://ec.europa.eu/education/higher-education/doc/report09_es.pdf

Council of the European Union. (2009). Council conclusions of May 12, 2009, for a strategic framework for European cooperation in Education and training. 2009/C119/02. Official Journal of the European Union. Retrieved November 2, 2011, from http://eur-lex.europa.eu/LexUriServ/LexUriServ.do?uri=OJ:C:2009:119:0002:0010:ES:PDF

European Commission. (2010). Lifelong Learning Programme. Statistical overview of the implementation of the decentralised actions in the Erasmus Programme in 2007/2008. Retrieved October 1, 2011, from http://ec.europa.eu/education/erasmus/doc/stat/0708/report.pdf

European Parliament. (2006). Decision N $\mathrm{N}^{\circ} 1720 / 2006 / \mathrm{CE}$ of the European Parliament and of the Council of November 15, 2006, by which an action program in the field of lifelong learning is established. Official Journal of the European Union. Strasbourg. 24.11.206.1327/45

Fernández Olmos, M. (2010). La movilidad: Sello distintivo del Espacio Europeo de Educación Superior [Mobility: The distinctive sign of the European Space of Higher Education]. Revista de Formación e Innovación Educativa Universitaria (REFIEDU), 3(3), 112-124.

Findlay, A., King, R., Smith, F., Geddes, A., \& Skeldon, R. (2012). World class? An investigation of globalisation, difference and international student mobility. Transactions of the Institute of British Geographers, 37(1), 118-131. http://dx.doi.org/10.1111/j.1475-5661.2011.00454.x

Hoffman, D. M. (2009). Changing academic mobility patterns and international migration: What will academic mobility mean in the $21^{\text {st }}$ century? Journal of Studies in International Education, 13(3), 347-364. http://dx.doi.org/10.1177/1028315308321374 
Kirsch, M., \& Beernaert, Y. (2011). Regards d'étudiants Erasmus [Regarding Erasmus students]. EDUCONSULT. Agence francophone pour l'éducation et la formation tout au long de la vie (AEF-Europe) Retrieved November 7, 2011, from http://www.aef-europe.be/documents/ ERA2011Regards_etudiants_Erasmus_06102011.pdf

Makal, J. (2007). The Erasmus staff and students' mobility as a good source of new educational experiences. Kaunas: Kaunas Univ.

Reding, V. (2004). Conferencia Premios Príncipe de Asturias de Cooperación Internacional [Conference at the Prince of Asturias Prizes for International Cooperation]. Oviedo 2004.

Rindoks, A. (2010). The international mobility of talent: Types, causes and development. Impact Journal of Ethnic and Migration Studies, 36(4), 709-710. http://dx.doi.org/10.1080/13691831003676751

Teichler, U. (2009). Internationalisation of higher education: European experiences. Asia Pacific Education Review, 10(1), 93-106. http://dx.doi.org/10.1007/s12564-009-9002-7

Thorn, K. (2009). The relative importance of motives for international self-initiated mobility. Career Development International, 14(4-5), 441-464. 